\title{
Place, Race, and Case: Examining Racialized Economic Segregation and COVID-19 in Louisiana
}

\author{
Jennifer L. Scott ${ }^{1} \cdot$ Natasha M. Lee-Johnson ${ }^{1} \cdot$ Denise Danos ${ }^{2}$
}

Received: 6 December 2021 / Revised: 9 February 2022 / Accepted: 10 February 2022 / Published online: 3 March 2022

(c) W. Montague Cobb-NMA Health Institute 2022

\begin{abstract}
Early COVID-19 pandemic data suggested racial/ethnic minority and low-income earning people bore the greatest burden of infection. Structural racism, the reinforcement of racial and ethnic discrimination via policy, provides a framework for understanding disparities in health outcomes like COVID-19 infection. Residential racial and economic segregation is one indicator of structural racism. Little attention has been paid to the relationship of infection to relative overall concentrations of risk (i.e., segregation of the most privileged from the most disadvantaged). We used ordinary least squares and geographically weighted regression models to evaluate the relationship between racial and economic segregation, measured by the Index of Concentration at the Extremes, and COVID-19 cases in Louisiana. We found a significant global association between racial segregation and cumulative COVID-19 case rate in Louisiana and variation across the state during the study period. The northwest and central regions exhibited a strong negative relationship indicating greater risk in areas with high concentrations of Black residents. On the other hand, the southeastern part of the state exhibited more neutral or positive relationships indicating greater risk in areas with high concentrations of White residents. Our findings that the relationship between racial segregation and COVID-19 cases varied within a state further support evidence that social and political determinants, not biological, drive racial disparities. Small area measures and measures of polarization provide localized information better suited to tailoring public health policy according to the dynamics of communities at the census tract level, which may lead to better health outcomes.
\end{abstract}

Keywords Residential segregation · COVID-19 · Built environment · Structural racism · Geographic weighted regression · Louisiana

Soon after the SARS-CoV-2 virus entered the USA in the early 2020, disparities in frequency and severity of COVID19 cases became apparent. Racial/ethnic minorities, particularly Black individuals, and people with low income bore the greatest burden of positive cases $[40,61,96,120]$ and deaths [93]. In a national study of veterans, Black veterans tested positive for COVID-19 at a rate of 16.4/1000 tests, nearly double the rate of White veterans [93]. Early evidence suggested COVID-19 advanced quicker through Black communities- $-90 \%$ of disproportionately Black counties reported a case, compared to $81 \%$ of all other counties at the time

Jennifer L. Scott

jenscott@1su.edu

1 School of Social Work, Louisiana State University, 2167 Pleasant Hall, Baton Rouge, LA 70803, USA

2 School of Public Health, Louisiana State University Health Sciences Center New Orleans, New Orleans, LA, USA
[85]. Examining localized geographies rendered these disparities even more dramatic. By April, Louisiana's Black residents comprised $70.0 \%$ of COVID-19 deaths, yet $32.8 \%$ of its population [27].

Structural racism, the reinforcement of racial/ethnic discrimination through policies that result in unequal opportunities or outcomes [7], provides a framework for understanding disparities in health like COVID-19 infection. Racial residential segregation, one indicator of structural racism given its link to policy decisions, is strongly associated with health disparities [2, 23, 36, 107, 116]. Examination of the role of the built environment, features of places in which people live and work, using area-based social measures ([ABSM]; e.g., neighborhood income, deprivation found several factors associated with COVID-19 cases, both demographic_racial composition $[1,69,75,96]$, poverty $[1,69]$,C. [122], and population density $[1,69,75,111$, 
114],C. [122]—and environmental, housing [69, 75, 96], transportation [69], and low air quality [96].

Built environment factors can be considered discretely; however, people considered disadvantaged according to one ABSM are often disadvantaged across multiple, suggesting that risk is multifaceted. Despite this, there has been little focus on infection as related to relative concentrations of risk (i.e., segregation of most advantaged from most disadvantaged). An exception, Chen and Krieger [24] found a positive association between COVID-19 deaths and Black low-income populations. This study is distinct because it uses the Index of Concentration at the Extremes (ICE), a segregation measure, to understand risk of COVID-19 death across spectrums of advantage [24]. It did not, however, consider spatial correlation. One other study using ICE found significant correlations between race/ethnicity and economic segregation and COVID-19 cases, however, analysis was at the county, not neighborhood, level and did not account for spatial correlation [17]. To better understand the role of concentrated risk, we examine the relationship between racial and economic segregation and COVID-19 cases in Louisiana, a state known for high racial and economic inequality and segregation $[4,42]$.

\section{Structural Racism and Segregation}

Efforts to suppress the social and economic mobility of $\mathrm{racial} / \mathrm{ethnic}$ minorities render it difficult to disentangle the separate effects of discrimination by race/ethnicity and socio-economic status [54]. Reinforcement of racial and ethnic discrimination by implementing policies resultant in unequal opportunities or outcomes, structural racism, occurs across sectors, i.e., housing, education, and health care [7, 37, 90]. Structural racism describes one aspect of systemic racism, a comprehensive theory integrating all racialized dimensions of society - the interlinking of racial discrimination, frames, hierarchies, institutions, and structural inequities [15, 30, 31]. It focuses on institutions and policies tied to inequitable outcomes [56, 57]. This structural focus on interlocking legal, political, and social mechanisms is key to understanding inequities in health.

Residential racial segregation, one indicator of structural racism [7], is linked to health disparities [2, 23, 36, 107, $116]$. In the USA, housing policy has explicitly and implicitly mandated residential racial segregation. Since formal slavery ended, mechanisms of segregation have taken different forms, evolving from explicit policy under the "separate but equal" doctrine of Plessy vs. Ferguson (163 U.S. 537 1896) to redlining, a practice wherein lenders outlined communities considered high risk for loans, disproportionately poor and Black, in red on maps leading to systematic denial of mortgages [46]. Black veterans of World War II also faced barriers to GI Bill benefits—low-interest mortgages [118] as white-owned financial institutions enabled loan denials [82], exacerbating Black-White wealth and homeownership gaps [45].

In tandem, White families began moving from cities to suburban communities [34]. This exodus, known as white flight, led to decreased city tax revenue and incentivized disinvestment in infrastructure, contributing to abandoned properties, crime, and urban decay $[34,106]$. Although the 1968 Fair Housing Act prohibited racial housing discrimination and thus legal redlining [92], evidence links lending discrimination to poor health outcomes [72]. Contemporaneously, investors and political actors capitalize on urban decay by purchasing and renovating structures at low cost to rent or sell at higher prices, a process termed gentrification [43]. White middle and upper-middle-class families move in, displacing Black and low-income residents [6, 38].

In Louisiana, slavery was replaced by sharecropping, an agricultural system wherein White landowners rented farmland to formerly enslaved people at high rates, further entrenching race and income inequalities [26]. In urban Louisiana, segregated housing projects were developed to house both Black and White residents with few economic resources; however, they soon became concentrated with Black residents [103]. Today, Black and low-income residents in Louisiana disproportionately live near chemical plants and oil refineries [53]. According to the Environmental Protection Agency, residents of northern and southwestern regions face higher exposure to air pollutants (e.g., particle matter (PM)) and risk for respiratory and immunological hazards [105], even though oil refineries are concentrated in southeastern Louisiana [44]. In southeastern Louisiana, an 85-mile stretch of predominately Black parishes between Baton Rouge and New Orleans houses over 150 factories. Higher rates of cancer, diabetes, heart problems, and asthma have been found there as compared to any other region, earning it the name "Cancer Alley" [102, 105]. Dioxin exposure has led to health issues so severe that at least one community has brought a case against the USA to the Inter-American Commission on Human Rights [47]. Southern Louisiana, home to the majority Black (59.5\%) city of New Orleans (US [108], is also experiencing "climate gentrification," increased investment in neighborhoods at higher elevations, and displacement of their residents [6]. Black residents living at higher elevations decreased in number, from $67.26 \%$ in 2000 to $59.58 \%$ in 2010, and, since Hurricane Katrina in 2005, have been increasingly displaced to New Orleans East, a lower elevation area with fewer hospitals, healthy food, and transit options, and increased crime rates [48]. 


\section{Built Environment, Residential Segregation, and Health}

Structural racism manifests in the built environment, affecting the health outcomes of residents $[28,116]$. The built environment structures access to both salubrious (e.g., public services, education, and employment) and detrimental (e.g., polluting industries, alcohol and food outlets) institutions [28]. Air pollutants (e.g., dioxins, particle matter (PM), and polycyclic aromatic hydrocarbons (PAHs)) are associated with health conditions, including diabetes, pulmonary disease, lung cancer, and asthma [74]. Emerging epigenetic research links PM and PAHs in the built environment to alterations in gene expression that affect health $[14,16]$.

One indicator measuring structural racism is residential segregation, the degree to which two or more social groups (e.g., race/ethnic, economic) live geographically separated $[78,116]$. Residential racial segregation, particularly White from Black neighborhoods, is associated with income and wealth disparities [116], overconcentration of payday lenders [41], alcohol outlets [13, 97], and fast-food restaurants [13, 66], as well as limited healthy food options [33] and disproportionately high air pollution [117]. Segregation has also been linked to health disparities like preterm births [3, 8] and infant mortality [49]. Several indicators have been developed to measure segregation: exposure measures the degree of interaction, centralization the degree of centralization, clustering the extent of accumulation, concentration the relative amount of space occupied, and evenness of geographic distributions [78]. Dissimilarity, an evenness measure common in public health research, estimates proportional differences between unevenly distributed groups [78].

Distinct as it accounts for both ends of the spectrum (i.e., most and least advantaged) in a single measure, the Index of Concentration at the Extremes (ICE) measures spatial concentration [77]. ICE produced stronger associations than the dissimilarity index (3.96 vs. 0.93 , respectively) in an analysis of assault type (e.g., fatal, non-fatal) and residential segregation [63]. ICE has been employed to examine relationships between social polarity and health outcomes, including hypertension [32], preterm births [22, 49, 98], infant mortality [11, $22,49,112]$, mortality (e.g., child, premature, and diseasespecific,[64, 65], and pregnancy-associated mortality [29]. Additionally, two studies using ICE to access county-level COVID-19 mortality rates found it produced the strongest positive relationships in comparison to other indicators of structural racism $[99,100]$.

\section{COVID-19, Race, and Income}

Aligning with national chronic and respiratory health trends [21], COVID-19 has been found to disproportionately affect Black and low-income communities $[1,75]$. "Non-white" communities suffer COVID-19 death rates nearly five times greater than White communities [24]. Predominately Black counties shoulder some of the highest case and death rates [85], and, of the 353 counties studied, Siegel and colleagues [100] found that $93 \%$ experienced a higher COVID-19 death rate among their Black as compared to their White population. Risk of severe COVID-19 complications is $19 \%$ greater for non-elderly lower income (less than $\$ 15,000$ annually) compared to higher income ( $\$ 50,000$ or greater annually) households [61]. Black, immigrant, less-educated, and low-wage workers are disproportionally employed in "frontline" positions, those essential to economic and health operations requiring in-person labor $[12,123]$ increasing risk of COVID-19 exposure, infection [94], and death [95].

Efforts to understand relationships between COVID-19 case rates, race/ethnicity, and income uncovered comorbidities and associations with environmental factors. People living in high-poverty neighborhoods are more likely to lack access to medical and public services [36] and develop chronic conditions [80]. Such conditions, specifically hypertension, diabetes, and pulmonary and cardiovascular diseases, are associated with severe COVID-19 infection [91, 124]. Environmental stressors like PM are also associated with severe COVID-19 symptoms and deaths in Black residents [85] and a $15 \%$ higher rate of COVID-19 deaths [119]. Factors related to chronic conditions and adverse COVID-19 outcomes vary regionally $[55,101]$. Black (58\%) and low-income people (38\%) disproportionately reside in southern states [59], where residents are more likely to be uninsured and have poorer health [5]. A preliminary descriptive analysis found that African Americans across four southern states (Louisiana, Mississippi, Alabama, Georgia) averaged $54 \%$ of all COVID-19 deaths, despite comprising $32 \%$ of the population [9].

Geographic patterns in comorbidities and environmental factors related to COVID-19 severity and case rates raise questions about the relationship between the built environment and COVID-19 risk. Studies employing areabased social measures (ABSMs) have identified several factors associated with infection, both demographicracial composition, poverty, population density-and environmental, housing, transportation, pollution $[1,69$, $75,96,111,114,122]$. Studies assessing risk using smallarea average and composite (e.g., social vulnerability) measures found associations with COVID-19 cases [25, 
$60,88]$. One analysis utilizing the dissimilarity index and Gini coefficient found faster COVID-19 case and mortality growth rates in cities with high Black-White or HispanicWhite segregation and income inequality [121].

By August 2021, Louisiana had 12,096 COVID-19 cases and 239 deaths per 100,000 residents, exceeding national rates of 10,660 cases and 184 deaths [19]. Racial disparities in death rate decreased yet remain moderately disproportionate, Black residents comprise $36.40 \%$ of deaths [68]. An analysis of Louisiana air quality connected higher PM exposure with greater shares of Black residents and COVID19 deaths [105]. Using the area deprivation Index (17 indicators like education, employment, housing), areas of high deprivation have a $40 \%$ greater risk of COVID-19 cases [73]. An analysis using the Social Vulnerability Index (15 indicators measuring four themes) found racial minority status and language the strongest predictor of cases [10].

Although ABSMs have identified associations with COVID-19 infection, studies have yet to account for spatial variation or examine concentrations of risk. We thus aimed to further clarify the relationship between environment and COVID-19 risk using the Index of Concentration at the Extremes (ICE) and accounting for spatial variation to examine the relationship between case rate and concentrations of race and income. We limited our analysis to Louisiana prior to vaccine availability to minimize possible confounding by variation in state COVID-19 reporting policies and behavior changes post vaccine arrival.

\section{Methods}

We linked administrative data from the Louisiana Department of Health (LDH) to population estimates to examine the relationship between COVID-19 case rate and three measures of residential segregation: racial, economic, and racial-economic. To assess global association, we first conducted ordinary least squares (OLS) regression. We then conducted geographic weighted regression (GWR) to account for spatially varying relationships.

\section{Data}

Administrative data on COVID-19 cases in Louisiana at the census tract level was obtained from LDH weekly reports on COVID-19 test and case numbers by census tract compiled in a publicly available dataset [67]. We linked this to the US Census Bureau's nationally representative American Community Survey (ACS) 5-year estimates (2018) using shapefiles with select demographic (race/ethnicity, population) and economic (income, poverty) indicators [109]. The study period spans the pandemic, from February 27-before Louisiana's first case-to December 2, 2020, the week vaccines first arrived in the USA [20]. Census tracts with populations less than $800(n=19)$ and without socio-economic data $(n=3)$ were excluded. The final dataset contained 1114 census tracts with complete information.

\section{COVID-19 Case Rate}

COVID-19 case rate was constructed as the cumulative number of cases in a tract during the study period divided by the total tract population (in thousands). The case rate was assumed to follow a log-normal distribution; thus, the outcome was log-transformed. Cumulative case rate by census tract is shown in Fig. 1.

\section{Racial and Economic Segregation}

We measured residential racial and economic segregation using the Index of Concentration at the Extremes (ICE), an indicator of spatial social polarization $[65,76]$. ICE reveals the extent of concentration at the extremes of deprivation and privilege within a geographic area, in this case the census tract. A value of -1 describes an area where $100 \%$ of the population is in the most disadvantaged group, a value of +1 describes an area where $100 \%$ of the population is in the most privileged group. ICE is calculated as follows:

$$
I C E_{i}=\left(A_{i}-P_{i}\right) / T_{i}
$$

Per census tract $i, A_{i}$ is number privileged persons, $P_{i}$ is number disadvantaged persons, and $T_{i}$ is total population with information on indicator (e.g., race, income) assessed [65]. We constructed three indices, one, a racial index ( $I C E_{R A C E}$; two, an economic index $\left(I C E_{E C O N}\right)$; and three, a racialized economic index $\left(I C E_{R A C E E C O N}\right)$. ICE $E_{R A C E}$ sets privileged/disadvantage extremes as the number of nonHispanic White and non-Hispanic Black residents, respectively. ICE $E_{E C O N}$ sets the extremes as the ACS categories most closely approximating cut points for 20th and 80th household annual income percentiles (more than $\$ 125,000$ and less than $\$ 25,000)$. Finally, ICE $E_{\text {RACEECON }}$ set extreme privilege as non-Hispanic White persons with income equal or greater than $\$ 125,000$, and extreme disadvantage as nonHispanic Black persons with income below $\$ 25,000$.

\section{Analysis}

Separately for each ICE indice, we first conducted OLS regression to examine the extent to which segregation predicts COVID-19 case rate. Spatial autocorrelation in OLS models was assessed by Global Moran's $I$ of the standardized residuals. We then conducted geographic weighted regression (GWR) to account for spatially varying relationships. OLS model results were reported as regression coefficients, 
Fig. 1 COVID-19 case rate by census tract

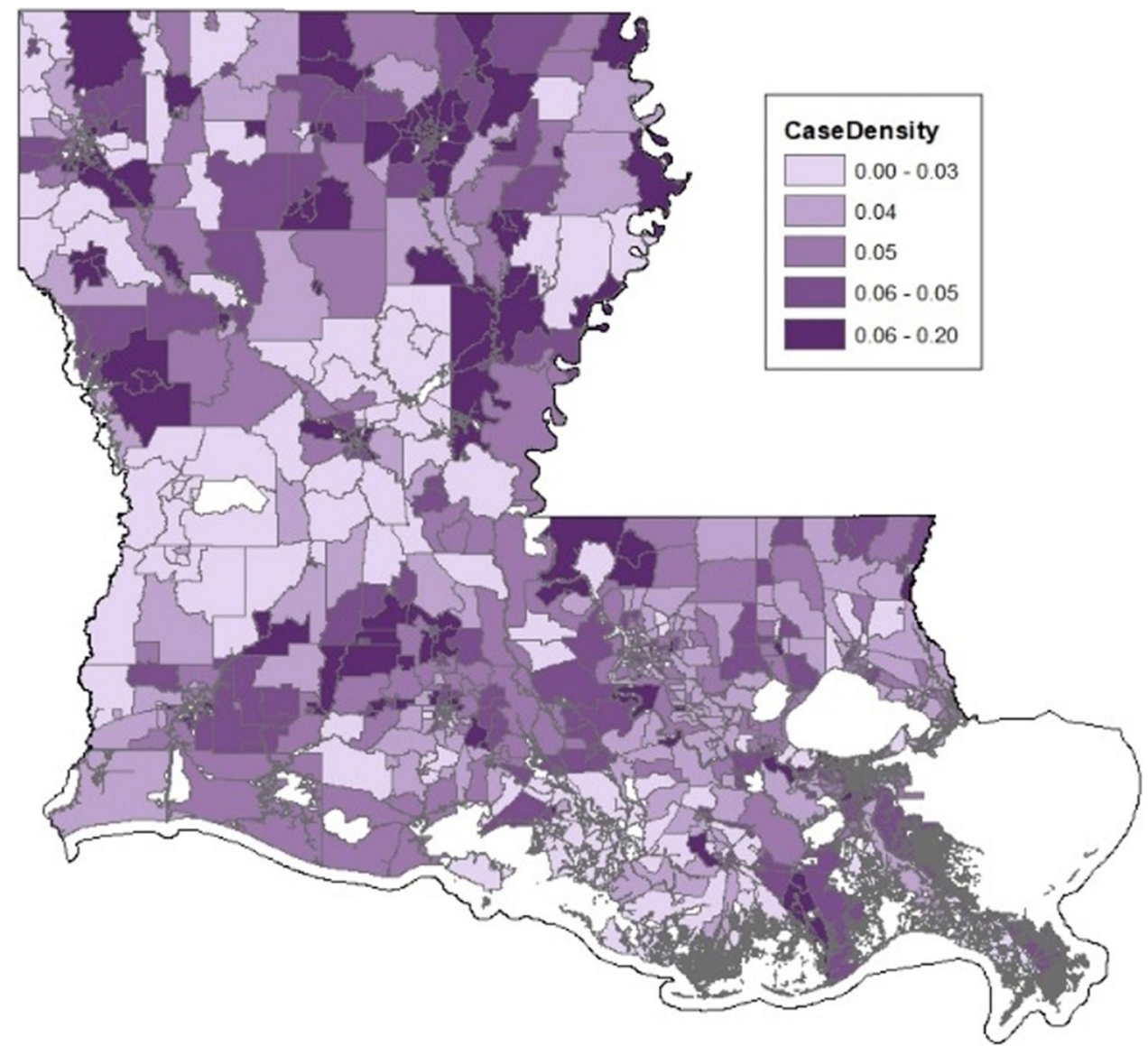

standard errors, and $p$ values. GWR model results were visualized using quantile maps of the coefficients. Model performance was evaluated by adjusted $R^{2}$ and Akaike's information criterion (AICc). ESRI ArcMap software version 10.8.1 was used for analyses and map construction.

The degree to which COVID-19 case rates truly reflect population infection rates depends upon adequate testing. Areas with high test positivity may underestimate the true population infection rate when compared to areas with low test positivity. Thus, we conducted a sensitivity analysis of case rate conditioned on test positivity, analyzing differences in observed and expected case rate given tract test positivity. Results from the sensitivity analysis are presented as Appendix Table 4.

\section{Results}

The study included 4.6 million residents, $31.9 \%$ Black or African American and 19.4\% living below the federal poverty threshold. Over the study period, there were a total of 210,194 confirmed COVID-19 cases in Louisiana, a total case rate of 4.519 per 1000 residents (Table 1). Overall, testing per capita was 0.68 . At the census tract level, the case
Table 1 COVID-19 cases and demographic estimates, Louisiana Overall and Census Tract $(n=1114)$

\begin{tabular}{llll}
\hline & & \multicolumn{2}{l}{ Tract summary } \\
\cline { 3 - 4 } & $\begin{array}{l}\text { Louisiana } \\
\text { Overall }\end{array}$ & Median & $\begin{array}{l}\text { Range } \\
\text { (Min-Max) }\end{array}$ \\
\hline Population $(N)$ & $4,650,917$ & 3,676 & $(816-18,524)$ \\
Cases $(N)$ & 210,194 & 164 & $(8-1,088)$ \\
Case rate (per 1000) & 0.045 & 0.043 & $(0.002-0.200)$ \\
Tests $(N)$ & $3,179,522$ & 2,320 & $(102-47,237)$ \\
Test rate (per capita) & 0.68 & 0.623 & $(0.042-11.287)$ \\
Black population $(\%)$ & 31.90 & 27.45 & $(0-99.8)$ \\
Poverty $(\%)$ & 19.36 & 18.6 & $(1.3-72.0)$ \\
ICE indices & & & $(-1.0$ to 0.99$)$ \\
Racial & 0.270 & 0.34 & $(-0.81$ to 0.64$)$ \\
Economic & -0.053 & --0.20 & $(-0.39$ to 0.23$)$ \\
Racial and economic & -0.007 & -0.01 & \\
\hline
\end{tabular}

rate ranged from 2 to 200 per 1000 residents, with a median rate of 43. Tests at the census tract level over the same period ranged from 102 to 47,237 (median 2320) with a per capita testing rate of 0.623 . Overall, Louisiana $I C E_{R A C E}$ was 0.270 with a census tract median of $0.340, I C E_{E C O N}$ was -0.053 
Table 2 Ordinary least squares regression results $(n=1114)$

\begin{tabular}{|c|c|c|c|c|c|c|c|c|c|}
\hline & \multicolumn{3}{|c|}{ Racial segregation } & \multicolumn{3}{|c|}{ Economic segregation } & \multicolumn{3}{|c|}{ Racial-economic segregation } \\
\hline & Estimate & SE & $p$ value & Estimate & SE & $p$ value & Estimate & SE & $p$ value \\
\hline Intercept & -3.144 & 0.011 & $<0.001$ & -3.151 & 0.014 & $<0.001$ & -3.157 & 0.011 & $<0.001$ \\
\hline ICE & -0.044 & 0.018 & 0.015 & 0.006 & 0.046 & 0.892 & -0.182 & 0.114 & 0.109 \\
\hline $\operatorname{Adj} R^{2}$ & 0.004 & & & -0.001 & & & 0.001 & & \\
\hline AICc & 858.769 & & & 864.634 & & & 862.084 & & \\
\hline Moran's I & 0.136 & & $<0.001$ & 0.122 & & $<0.001$ & 0.130 & & $<0.001$ \\
\hline
\end{tabular}

Table 3 Geographically weighted regression results $(n=1114)$

\begin{tabular}{lccc}
\hline & Racial segregation & $\begin{array}{l}\text { Economic } \\
\text { segregation }\end{array}$ & $\begin{array}{l}\text { Racial- } \\
\text { economic } \\
\text { segregation }\end{array}$ \\
\hline Adj $R^{2}$ & 0.241 & 0.233 & 0.238 \\
AICc & 584.083 & 595.629 & 588.810 \\
\hline
\end{tabular}

with a census tract median of -0.200 , and $I C E_{\text {RACEECON }}$ was -0.007 with a census tract median of -0.010 .

OLS models, shown in Table 2, indicated a significant global association between COVID-19 case rates and $I C E_{R A C E}(p=0.015)$, areas with greater concentrations of Black residents had higher case rates. However, the adjusted $R^{2}$ was 0.004 , indicating that the global association only explained $0.4 \%$ of the variation. Significant spatial autocorrelation was present in all OLS models (all $p<0.001$ ) suggesting geography played a significant role in the variance in COVID-19 case rate, not unexpected given the airborne mechanism of virus transmission.

Accounting for spatial autocorrelation with GWR models (Table 3) exhibited better model fit compared to OLS models. Overall, the GWR model of the relationship between COVID-19 case rates and ICE $E_{R A C E}$ exhibited the best fit
$(\mathrm{AICc}=584.08)$. This model explained approximately $24.1 \%$ of variation in COVID-19 case rates.

The map of $I C E_{R A C E}$ from the GWR model is shown in Fig. 2. The $I C E_{R A C E}$ index is represented on a continuum, from the brightest red indicating a strong negative relationship between $I C E_{R A C E}$ and COVID-19 cases (i.e., high concentrations of black residents and COVID-19 incidence), the brightest blue indicating a strong positive relationship between ICE $E_{R A C E}$ and COVID-19 cases (i.e., high concentrations of white residents and COVID-19 incidence), and yellow representing areas where there was no relationship between racial segregation and COVID-19 case rate. The variation in this relationship across the state is notable. The northwest and central parts of the state exhibited a strong negative (red) relationship between $I C E_{R A C E}$ and cases, indicating greater risk for COVID-19 infection in areas with high concentrations of Black residents. In contrast, the southeastern part of the state exhibited more neutral (yellow) or positive (blue) relationships between $I C E_{R A C E}$ and COVID-19 cases, indicating areas with no relationship ranging to those where a greater risk for COVID-19 infection was found in areas with high concentrations of White residents.

As census tracts are typically smaller and denser in metropolitan areas, Fig. 3 maps $I C E_{R A C E}$ for the 5 major metropolitan areas: Baton Rouge, Lafayette, Lake Charles, New Orleans,
Fig. 2 Racial segregation on COVID-19 case rate

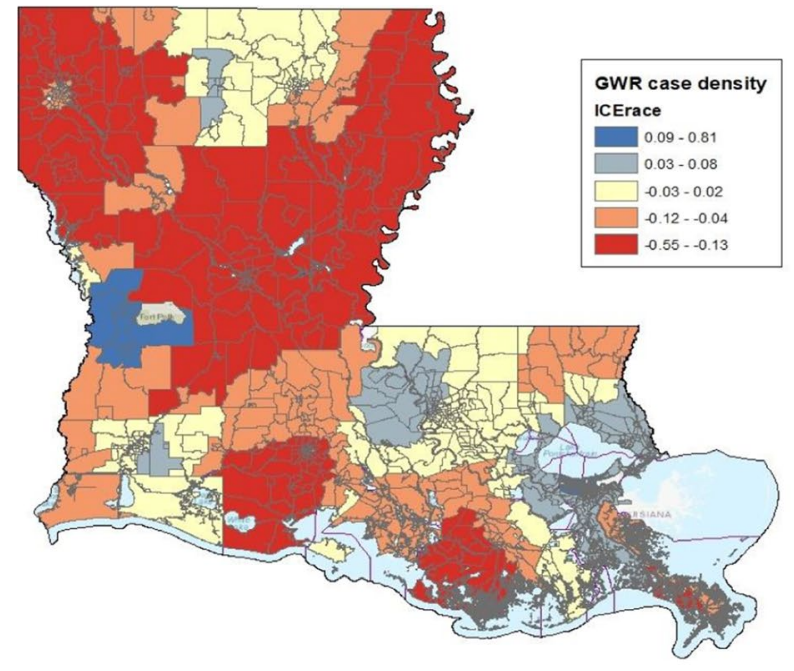

Local $\mathrm{R}^{2}$

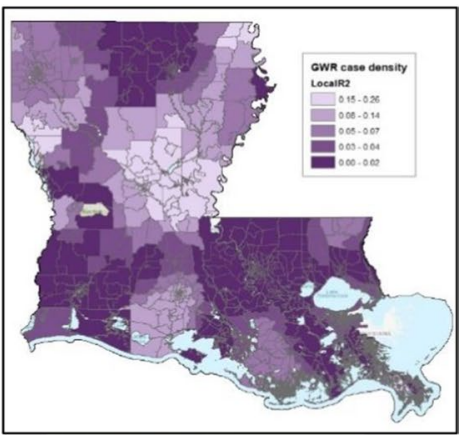


Fig. 3 Racial segregation on COVID-19 case rate, major urban areas a. Baton Rouge, b. Lafayette, c. Lake Charles, $\mathbf{d}$. New Orleans, e. Shreveport

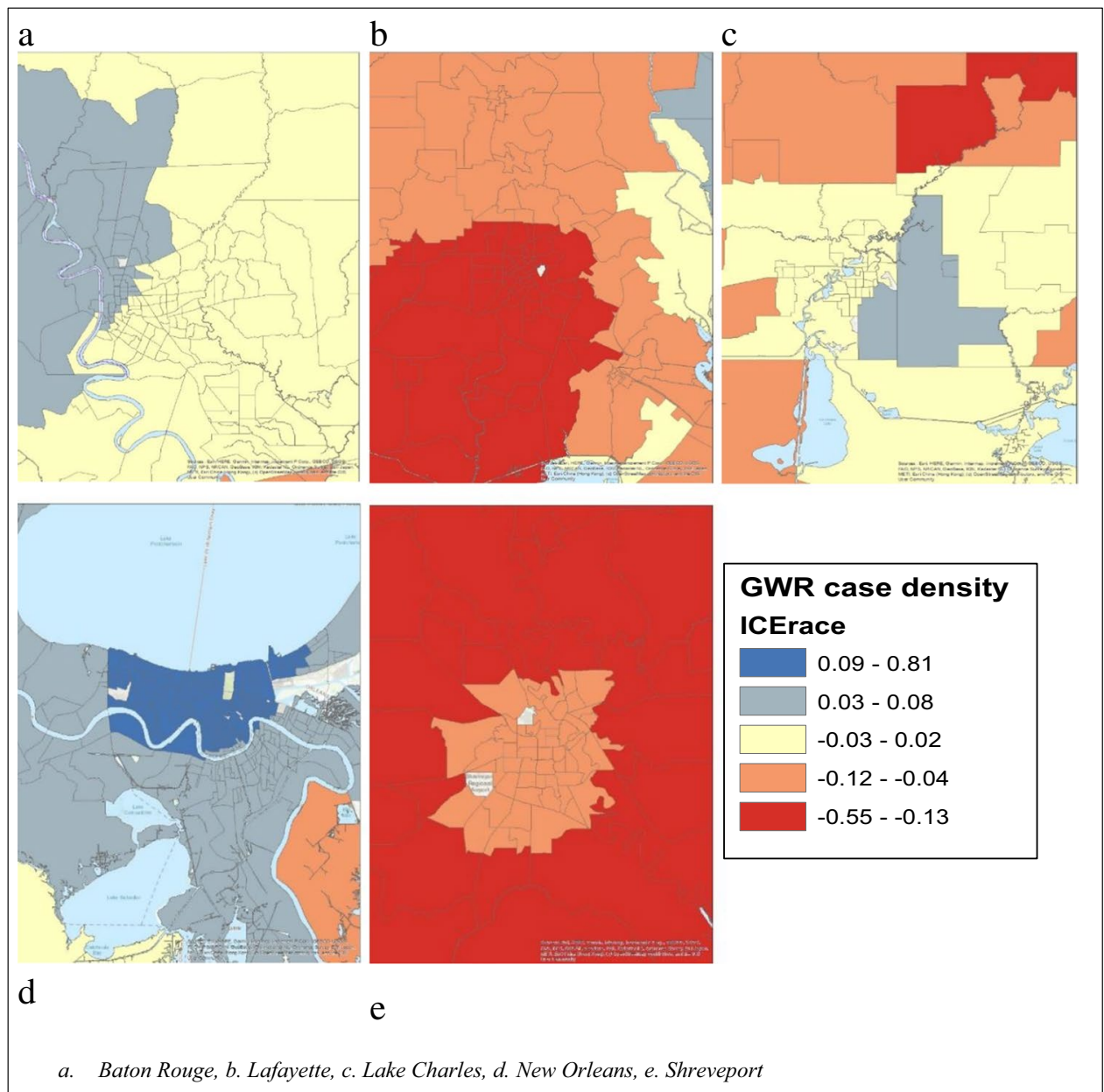

and Shreveport. In the New Orleans area, there was a positive relationship between ICE $E_{R A C E}$ and COVID-19 cases. The Baton Rouge area also exhibited positive or neutral relationships. In contrast, we observed negative relationships between $I C E_{R A C E}$ and cases in Lafayette, Lake Charles, and Shreveport, located in the northwestern and central regions. In Lafayette and Shreveport, the strongest negative relationship was just outside the metropolitan core.

The GWR models examining the relationship between COVID-19 cases and ICE $E_{E C O N}$, and ICE $E_{R A C E E C O N}$ had slightly smaller adjusted $R^{2}$ values $(0.238$ and 0.233$)$, indicating slightly poorer fit than that of the $I C E_{R A C E}$ model (Table 3). Trends in the variation of the relationship between the indices and COVID-19 cases across the state were similar, negative in the northwest and central regions, and neutral or positive relationships in the southwest and southeast regions (Figs. 4 and 5).

\section{Discussion}

We found a significant global association between residential racial segregation and cumulative COVID-19 case rate in Louisiana. This relationship varied across the state. These state-level findings are consistent with recent research, including one national study that found significant association between residential segregation and COVID-19 outcomes [24], and other national studies focusing on concentration (rather than segregation) of Black and Hispanic residents and income inequality [35, $70,104]$. However, one longitudinal study found the relationship between income inequality and COVID-19 cases weakened over time, suggesting inequality may be strongest before the virus becomes pervasive [104]. 
Fig. 4 Economic segregation on COVID-19 case rates
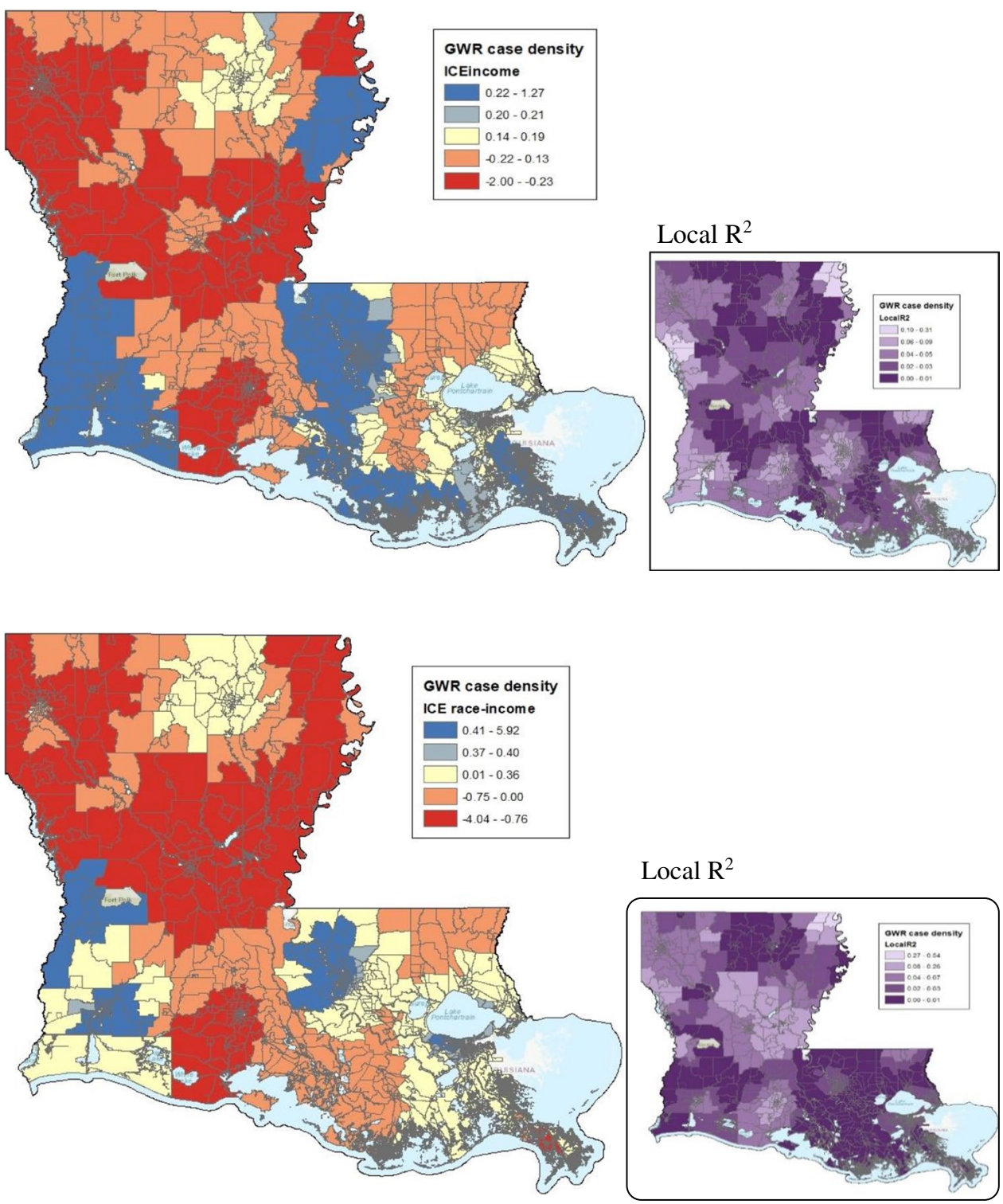

Fig. 5 Racial and economic segregation on COVID-19 case rates
These prior studies observed county-level case rates, which can introduce bias [83], and did not control for geographically varying relationships. Our findings further clarify the relationships between race and income and COVID-19 in two ways. First, we examined small-area residential segregation measured by ICE $[65,78]$ rather than share of disadvantaged residents. Second, we conducted GWR to account for geographic variation. COVID19 case rate was associated with high concentrations of Black/African American residents in central and northern regions and rural Louisiana. In contrast, cumulative COVID-19 case rate in southeastern Louisiana had either no association with racial segregation or positive association with a high concentration of White residents (Fig. 2). This counters spatial studies that reported strong local relationships between COVID-19 and social determinants, including race, in the southeast early in the pandemic [60, 87].

Three factors may explain this lack of a cumulative association, separately or in combination. The southeast region includes the two largest metropolitan areas (New Orleans and Baton Rouge). One possibility is that racial disparities in COVID-19 may be most pronounced initially and level off as the virus spreads [51,87, 104]. A second possibility is that testing and prevention strategies targeting vulnerable populations early in the pandemic effectively reduced racial disparities in this region over time [89]. The greater New Orleans area, one of the earliest and most intense COVID-19 hotspots [52], was one of four cities selected for a federal "community testing" pilot program beginning March 20, 2020 [18, 113]. Baton Rouge followed, the federal government announcing it would be one of three surge testing sites 
(the others in Florida and Texas) from July 7 to 18, 2020 [71, 110]. Concentrated testing did not occur throughout the rest of Louisiana until testing became widely available.

A third possible explanation considers the increasing politicization of COVID-19 prevention measures. In a new working paper analyzing the Delta variant surge period, Krieger and colleagues [62] demonstrated that political lean (Republican vs. Democrat in 2020 presidential election) was one of two county-level variables most sharply differentiating COVID-19 risk and mortality. Political lean combined with racialized economic segregation (measured by ICE) had the greatest association with both risk and death [62]. Another national study found state-level policy decisions like ACA and Medicaid expansion, but not political characteristics (e.g., governor's party, voting behavior), associated with lower COVID-19 rates [70]. The strong early relationship between race and COVID-19 cases shifted as the virus spread and as Black, Native, and Hispanic communities were targeted by community testing [39] and vaccination campaigns [115]. Simultaneously, anti-vaccination and anti-prevention sentiment increased among predominantly Republican and White communities [58, 84, 86]. The relationship of combined racial segregation and county-level political lean to COVID-19, or similarly politicized public health issues, could warrant further investigation. These spatial patterns in COVID-19 case rate at the census tract level suggest messaging in vaccine campaigns nuanced to local (rather than state) level perspectives may improve uptake.

Though our findings suggest clear associations between racial and economic segregation and cumulative COVID19 case rate, they should be considered in the context of certain limitations. As an observational study, associations ought not be interpreted as causal. In other words, neither race nor income is determinative of COVID-19 incidence. A key contribution of our study is the geographic scale of analysis. Focusing on COVID-19 case rate and segregation at the census tract-level illuminated local patterns; however, analytical tradeoffs were required. The small size of some census tracts translates to a higher potential that individuals could be identified; thus, LDH does not make COVID-19 data disaggregated by demographics (e.g., age, race/ethnicity) and other outcomes (e.g., hospitalization, mortality) publicly available at the census tract level. Given our interest in local variation and the few studies that disaggregate at a scale smaller than county-level, we prioritized census tract-level analysis. This also limited our ability to model the results using direct standardized age- or race-adjusted rates at the census tract-level. As prior studies have found that age-standardization produced a wider Black-White disparity in COVID-19 mortality at the state level, our estimates of the gap may be conservative $[99,100]$.

Additionally, the analysis was unadjusted for population density and rurality, as these factors are not assumed to be independent of residential segregation. The extremes of racial segregation tend to occur in densely populated metropolitan areas, a phenomenon described as "hypersegregation" [79, 81]. Future analysis could explore potential mediating or moderating effects of these factors. Finally, the current study does not account for temporal or longitudinal trends. Time or time-sensitive variables (e.g., rate of community spread, testing capacity/strategy, public health policies) may modify the effect of segregation on infection rates.

Nevertheless, our findings that the relationship between racial segregation and COVID-19 cases varies geographically within a state further support evidence that social and political determinants, not biological, drive racial disparities. Small area and polarization measures provide localized information better suited to tailoring public health policy. Also, emerging evidence suggests that narrowly tailored community testimony/messaging is an effective strategy to increase vaccine uptake [50]. Recognizing the role of inequality, targeted testing, vaccination, and other public health efforts aligned with community dynamics—racial, economic, and political-at the census tract level may produce better health outcomes.

\section{Appendix}

Table 4

Table 4 Case positivity analysis

\begin{tabular}{|c|c|c|c|c|}
\hline & \multicolumn{2}{|l|}{ OLS } & \multicolumn{2}{|l|}{ GWR } \\
\hline & Estimate & SE & $p$ value & Estimate \\
\hline \multicolumn{5}{|c|}{ Racial Segregation } \\
\hline Intercept & 0.029 & 0.031 & 0.352 & \\
\hline ICE & -0.158 & 0.051 & 0.002 & \\
\hline $\operatorname{Adj} R^{2}$ & 0.008 & & & 0.237 \\
\hline $\mathrm{AICc}$ & 3155.90 & & & 2890.92 \\
\hline Moran's I & 0.100 & & & \\
\hline \multicolumn{5}{|c|}{ Economic segregation } \\
\hline Intercept & 0.003 & 0.038 & 0.947 & \\
\hline ICE & 0.014 & 0.128 & 0.914 & \\
\hline $\operatorname{Adj} R^{2}$ & -0.001 & & & 0.227 \\
\hline $\mathrm{AICc}$ & 3165.40 & & & 2904.49 \\
\hline Moran's I & 0.089 & & & \\
\hline \multicolumn{5}{|c|}{ Racial-economic segregation } \\
\hline Intercept & -0.015 & 0.031 & 0.634 & \\
\hline ICE & -0.634 & 0.319 & 0.047 & \\
\hline $\operatorname{Adj} R^{2}$ & 0.003 & & & 0.233 \\
\hline $\mathrm{AICc}$ & 3161.47 & & & 2896.302 \\
\hline Moran's $I$ & 0.096 & & & \\
\hline
\end{tabular}


Author Contribution Dr. Jennifer Scott-Developed concept; performed all data analyses; developed manuscript outline; supported writing of introduction, literature review, and discussion; wrote methods and results section; revised full manuscript.

Natasha Lee-Johnson-Wrote literature review and introduction, revised full manuscript.

Dr. Denise Danos-Discussed and provided feedback on data analyses and interpretation; drafted part of initial discussion section; contributed to writing methods and results; revised full manuscript.

Availability of Data and Material Data used is publicly available from the Louisiana Department of Health and the US Census Bureau.

Code availability Not available.

\section{Declarations}

Ethics approval IRB Approval from Louisiana State University.

Consent to Participate Not applicable.

Consent for Publication Not applicable.

Conflict of interest The authors declare no competing interests.

\section{References}

1. Abedi V, Olulana O, Avula V, Chaudhary D, Khan A, Shahjouei S, Li J, Zand R. Racial, economic, and health inequality and COVID-19 infection in the United States. J Racial Ethn Health Disparities. 2020;1-11.

2. Ahmed A, Mohammed S, Williams D. Racial discrimination \& health: Pathways \& evidence. Indian J Med Res. 2007;126(4):318-27.

3. Anthopolos R, Kaufman J, Messer L, Miranda M. Racial residential segregation and preterm birth: built environment as a mediator. Epidemiology. 2014;25(3):397-405.

4. Apergis N, Dincer O, Payne J. The relationship between corruption and income inequality in U.S. states: evidence from a panel cointegration and error correction model. Public Choice. 2010;145(1-2):125-35.

5. Artiga S, Damico A. Health and health coverage in the south: A data update. Kaiser Family Foundation; 2016.

6. Aune K, Gesch D, Smith G. A spatial analysis of climate gentrification in Orleans parish, Louisiana post hurricane Katrina. Environ Res. 2020;185:109384.

7. Bailey Z, Krieger N, Agénor M, Graves J, Linos N, Bassett M. Structural racism and health inequities in the USA: evidence and interventions. Lancet. 2017;389(10077):1453-63.

8. Beck A, Edwards E, Horbar J, Howell E, McCormick M, Pursley D. The color of health: how racism, segregation, and inequality affect the health and well-being of preterm infants and their families. Pediatr Res. 2020;87(2):227-34.

9. Betson N, Maitra A. Disproportionate COVID-19 related mortality amongst African Americans in four southern states in the United States [Preprint]. Epidemiology. 2020.

10. Biggs E, Maloney P, Rung A, Peters E, Robinson W. The relationship between social vulnerability and COVID-19 incidence among Louisiana census tracts. Front Public Health. 2021;8:617976.
11. Bishop-Royse J, Lange-Maia B, Murray L, Shah R, DeMaio F. Structural racism, socio-economic marginalization, and infant mortality. Public Health. 2021;190:55-61.

12. Blau F, Koebe J, Meyerhofer P. Who are the essential and frontline workers? Bus Econ. 2021;56(3):168-78.

13. Block J, Scribner R, DeSalvo K. Fast food, race/ethnicity, and income. Am J Prev Med. 2004;27(3):211-7.

14. Bollati V, Baccarelli. Environmental epigenetics. Heredity. 2010;105(1):105-12.

15. Bonilla-Silva E. Rethinking racism: toward a structural interpretation. Am Sociol Rev. 1997;62(3):465.

16. Breton C, Marutani A. Air pollution and epigenetics: recent findings. Curr Environ Health Rep. 2014;1(1):35-45.

17. Brown K, Lewis J, Davis S. An ecological study of the association between neighborhood racial and economic residential segregation with COVID-19 vulnerability in the United States' capital city. Ann Epidemiol. 2021;59:33-6.

18. Cantrell L. Drive-through COVID-19 testing to be offered to healthcare workers and first responders at two new orleans sites. City of New Orleans. 2020.

19. CDC. CDC COVID data tracker. COVID Data Tracker. 2021a.

20. CDC. CDC museum COVID-19 timeline. Center for Disease Control and Prevention; 2021b.

21. Celedón J, Roman J, Schraufnagel D, Thomas A, Samet J. Respiratory health equality in the United States. The American Thoracic Society Perspective; 2014.

22. Chambers B, Baer R, McLemore M, Jelliffe-Pawlowski L. Using index of concentration at the extremes as indicators of structural racism to evaluate the association with preterm birth and infant mortality-California, 2011-2012. J Urban Health. 2019;96(2):159-70.

23. Chang-Martinez C, Ahmed N, Natale R. Residential segregation, neighborhood social and physical context in obesity disparities in Hispanic preschoolers: a conceptual model. J Health Disparities Res Pract. 2017;10(2):38-60.

24. Chen J, Krieger N. Revealing the unequal burden of COVID19 by income, race/ethnicity, and household crowding: US county versus zip code analyses. J Public Health Manag Pract. 2021;27(1):S43-56.

25. Dasgupta S, Bowen V, Leidner A, Fletcher K, Musial T, Rose C, Cha A, Kang G, Dirlikov E, Pevzner E, Rose D, Ritchey M, Villanueva J, Philip C, Liburd L, Oster A. Association between social vulnerability and a county's risk for becoming a COVID-19 hotspot-United States, June 1-July 25, 2020. Morb Mortal Wkly Rep. 2020;69(42):1535-41.

26. de Greta J. "With the aid of god and the F.S.A.": the Louisiana farmers' union and the African American freedom struggle in the new deal era. J Soc Hist. 2000;34(1):105-39.

27. Deslatte M. Louisiana data: Virus hits blacks, people with hypertension. Associated Press; 2020.

28. Diez Roux A, Mair C. Neighborhoods and health: Neighborhoods and health. Ann N Y Acad Sci. 2010;1186(1):125-45.

29. Dyer L, Chambers B, Crear-Perry J, Theall K, Wallace M. The index of concentration at the extremes (ICE) and pregnancyassociated mortality in Louisiana, 2016-2017. Matern Child Health J. 2021.

30. Feagin J. Systemic racism: a theory of oppression. Routledge; 2006.

31. Feagin J, Bennefield Z. Systemic racism and U.S. health care. Soc Sci Med. 2014;103:7-14.

32. Feldman J, Waterman P, Coull B, Krieger N. Spatial social polarisation: Using the index of concentration at the extremes jointly for income and race/ethnicity to analyse risk of hypertension. J Epidemiol Community Health. 2015;69(12):1199-207. 
33. Franco M, Diez Roux A, Glass T, Caballero B, Brancati F. Neighborhood characteristics and availability of healthy foods in Baltimore. Am J Prev Med. 2008;35(6):561-7.

34. Frey W. Central city white flight: racial and nonracial causes. Am Sociol Rev. 1979;44(3):425.

35. Gaglioti A, Li C, Douglas M, Baltrus P, Blount M, Zahidi R, Caplan L, Willock R, Fasuyi O, Mack D. Population-level disparities in COVID-19: measuring the independent association of the proportion of black population on COVID-19 cases and deaths in US counties. J Public Health Manag Pract. 2021;27(3):268-77.

36. Gaskin D, Dinwiddie G, Chan K, McCleary R. Residential segregation and disparities in health care services utilization. Med Care Res Rev. 2012;69(2):158-75.

37. Gee G, Ford C. Structural racism and health inequities: old issues, new directions. Du Bois Rev. 2011;8(1):115-32.

38. Gibbons, J. (2019). Are gentrifying neighborhoods more stressful? A multilevel analysis of self-rated stress. SSM - Population Health, 7, 100358.

39. Golden S. Coronavirus risk factors and people of color. Hopkins Medicine; 2020.

40. Goyal M, Simpson J, Boyle M, Badolato G, Delaney M, McCarter R, Cora-Bramble D. Racial and/or ethnic and socioeconomic disparities of SARS-CoV-2 infection among children. Pediatrics. 2020;146(4).

41. Graves S. Landscapes of predation, landscapes of neglect: A location analysis of payday lenders and banks. Prof Geogr. 2003;55(3):303-17.

42. Groegar L, Waldman A, Eads D. Miseducation: is there racial inequality at your school? ProPublica; 2018.

43. Hackworth J, Smith N. The changing state of gentrification. Tijdschr Econ Soc Geogr. 2001;92(4):464-77.

44. Hemmerling S, DeMyers C, Parfait J. Tracing the flow of oil and gas: a spatial and temporal analysis of environmental justice in coastal Louisiana from 1980 to 2010 . Environ Justice. 2021;14(2):134-45.

45. Herring C, Henderson L. Wealth inequality in black and white: cultural and structural sources of the racial wealth gap. Race Soc Probl. 2016;8(1):4-17.

46. Hillier A. Redlining and the home owners' loan corporation. J Urban Hist. 2003;29(4):394-420.

47. Hines R. The price of pollution: the struggle for environmental justice in Mossville, Louisiana. West J Black Stud. 2015;39(3):198-208.

48. Housing Authority of New Orleans. Assessment of fair housing tool. Housing Authority of New Orleans; 2016.

49. Huynh M, Spasojevic J, Li W, Maduro G, Van Wye G, Waterman P, Krieger N. Spatial social polarization and birth outcomes: preterm birth and infant mortality - New York City, 2010-14. Scand J Public Health. 2018;46(1):157-66.

50. Ignacio M. Community-based strategies to increase COVID19 vaccine acceptance among urban American Indian/Alaska Natives living in Southern Arizona [Paper presentation]. Society for Social Work and Research $26^{\text {th }}$ Annual Conference. Washington, D.C. 2022. https://sswr.confex.com/sswr/2022/ webprogram/Paper47899.html.

51. Islam S, Nayak A, Hu Y, Mehta A, Dieppa K, Almuwaqqat Z, Ko Y, Patel S, Goyal A, Sullivan S, Lewis T, Vaccarino $\mathrm{V}$, Morris A, Quyyumi A. Temporal trends in the association of social vulnerability and race/ethnicity with county-level COVID-19 incidence and outcomes in the USA: An ecological analysis. BMJ Open. 2021;11(7).

52. Jervis R, Clark M, Reyes L. Death rate soars in New Orleans coronavirus "disaster" that could define city for generations. USA Today; 2020.
53. Jervis R, Gomez A. Racism turned their neighborhood into "Cancer Alley." Now they're dying from COVID-19. USA Today; 2020.

54. Johnson D. Disentangling poverty and race. Appl Dev Sci. 2000;4(sup1):55-67.

55. Johnston C, Chen R. The COVID-19 pandemic and its impact on the southern United States. J Comp Fam Stud. 2020;51(3-4):314-23.

56. Jones C. Levels of racism: a theoretic framework and a gardener's tale. Am J Public Health. 2000;90(8):1212-5.

57. Jones C. Invited commentary: "race," racism, and the practice of epidemiology. Am J Epidemiol. 2001;154(4):299-304.

58. Jurkowitz M, Mitchell A. American relied most on Trump COVID-19 news among least likely to be vaccinated. Pew Research Center; 2021.

59. Kaiser Family Foundation. Distribution of total population by federal poverty level. 2019.

60. Karaye I, Horney J. The impact of social vulnerability on COVID-19 in the US: an analysis of spatially varying relationships. Am J Prev Med. 2020;59(3):317-25.

61. Koma W, Artiga S, Neuman T, Claxton G, Rae M, Kates J, Michaud J. Low-income and communities of color at higher risk of serious illness if infected with coronavirus. Kaiser Family Foundation; 2020.

62. Krieger, N., Chen, J., Testa, C., Waterman, P., \& Hanage, W. (2021). Political lean: A crucial variable for monitoring COVID19 in the United States. Harvard Center for Population and Development Studies (HCPDS) Working Paper, 21(5).

63. Krieger N, Feldman J, Waterman P, Chen J, Coull B, Hemenway D. Local residential segregation matters: Stronger association of census tract compared to conventional city-level measures with fatal and non-fatal assaults (total and firearm related), using the index of concentration at the extremes (ICE) for racial, economic, and racialized economic segregation, Massachusetts (US), 19952010. J Urban Health. 2017;94(2):244-58.

64. Krieger N, Kim R, Feldman J, Waterman P. Using the index of concentration at the extremes at multiple geographical levels to monitor health inequities in an era of growing spatial social polarization: Massachusetts, USA (2010-14). Int J Epidemiol. 2018;47(3):788-819.

65. Krieger N, Waterman P, Spasojevic J, Li W, Maduro G, Van Wye G. Public health monitoring of privilege and deprivation with the index of concentration at the extremes. Am J Public Health. 2016;106(2):256-63.

66. Kwate N. Fried chicken and fresh apples: racial segregation as a fundamental cause of fast food density in black neighborhoods. Health Place. 2008;14(1):32-44.

67. LDH. COVID-19 information. Ldh.La.Gov. 2021a.

68. LDH. Additional COVID-19 data department of health state of Louisiana. 2021b.

69. Lewis N, Friedrichs M, Wagstaff S, Sage K, LaCross N, Bui D, McCaffrey K, Barbeau B, George A, Rose C, Willardson S, Carter A, Smoot C, Nakashima A, Dunn A. Disparities in COVID-19 incidence, hospitalizations, and testing, by area-level deprivation-Utah, March 3-July 9, 2020. Morb Mortal Wkly Rep. 2020;69(38):1369-73.

70. Liao T, De Maio F. Association of social and economic inequality with coronavirus disease 2019 incidence and mortality across US counties. J Am Med Assoc. 2021;4(1).

71. Louisiana Department of Environmental Quality. Federal government stands up free testing sites in Baton Rouge, a national "hotspot." Louisiana Department of Environmental Quality; 2020.

72. Lynch E, Malcoe L, Laurent S, Richardson J, Mitchell B, Meier $\mathrm{H}$. The legacy of structural racism: associations between historic redlining, current mortgage lending, and health. SSM - Popul Health. 2021;14:100793. 
73. Madhav K, Oral E, Straif-Bourgeois S, Rung A, Peters E. The effect of area deprivation on COVID-19 risk in Louisiana. PLOS ONE. 2020;15(12).

74. Manisalidis I, Stavropoulou E, Stavropoulos A, Bezirtzoglou E. Environmental and health impacts of air pollution: a review. Front Public Health. 2020;8:14.

75. Maroko A, Nash D, Pavilonis B. Covid-19 and inequity: a comparative spatial analysis of New York City and Chicago hot spots. J Urban Health Bull New York Acad Med. 2020;97(4):461-70.

76. Massey D. Residential segregation and neighborhood conditions in U.S. metropolitan areas. In: Smelser N, Wilson W, Mitchell F, editors. America becoming: racial trends and their consequences, vol. 1. National Academies Press; 2001. p. 391-434.

77. Massey D. The prodigal paradigm returns: ecology comes back to sociology. In: Booth A, Crouter A, editors. Does it take a village? Community effects on children, adolescents, and families. Psychology Press; 2001.

78. Massey D, Denton N. The dimensions of residential segregation. Soc Forces. 1988;67(2):281-315.

79. Massey D, Denton N. Hypersegregation in U.S. metropolitan areas: black and Hispanic segregation along five dimensions. Demography. 1989;26(3):373-91.

80. Massey D, Fischer M. How segregation concentrates poverty. Ethn Racial Stud. 2000;23(4):670-91.

81. Massey D, Tannen J. A research note on trends in black hypersegregation. Demography. 2015;52(3):1025-34.

82. McKenna C. The homeownership gap: How the post-World War II GI bill shaped modern day homeownership patterns for black and white Americans [Masters, Massachusetts Institute of Technology]. 2008.

83. Meilleur A, Subramanian S, Plascak J, Fisher J, Paskett E, Lamont E. Rural residence and cancer outcomes in the United States: issues and challenges. Cancer Epidemiol Biomark Prev. 2013;22(10):1657-67.

84. Miller J. Psychological, political, and situational factors combine to boost COVID-19 conspiracy theory beliefs. Can J Polit Sci. 2020;53(2):327-34.

85. Millett G, Jones A, Benkeser D, Baral S, Mercer L, Beyrer C, Honermann B, Lankiewicz E, Mena L, Crowley JS, Sherwood J, Sullivan PS. Assessing differential impacts of COVID-19 on black communities. Ann Epidemiol. 2020;47:37-44.

86. Mitchell A, Jurkowitz M, Oliphant J, Shearer E. How Americans navigated the news in 2020: a tumultuous year in review. Pew Research Center; 2021. p. 54.

87. Mollalo A, Vahedi B, Rivera K. GIS-based spatial modeling of COVID-19 incidence rate in the continental United States. Sci Total Environ. 2020;728:138884.

88. Nayak, A., Islam, S., Mehta, A., Ko, Y., Goyal, A., Sullivan, S., Lewis, T., Vaccarino, V., Morris, A., Quyyumi, A., Nayak, D., \& Islam, D. (2020). Impact of social vulnerability on COVID-19 incidence and outcomes in the United States. 27.

89. Oates G, Juarez L, Horswell R, Chu S, Miele L, Fouad M, Curry W, Fort D, Hillegass W, Danos D. The association between neighborhood social vulnerability and COVID-19 testing, positivity, and incidence in Alabama and Louisiana. J Community Health. 2021

90. Powell J. Structural racism: building upon the insights of John Calmore. North Carolina Law Rev. 2008;86(3):26.

91. Pranata R, Huang I, Lim M, Wahjoepramono E, July J. Impact of cerebrovascular and cardiovascular diseases on mortality and severity of COVID-19-systematic review, meta-analysis, and meta-regression. J Stroke Cerebrovasc Dis. 2020;29(8):104949.

92. Quillian L, Lee J, Honoré B. Racial discrimination in the U.S. housing and mortgage lending markets: a quantitative review of trends, 1976-2016. Race Soc Probl. 2020;12(1):13-28.
93. Rentsch C, Kidwai-Khan F, Tate J, Park L, King J, Skanderson M, Hauser R, Schultze A, Jarvis C, Holodniy M, Lo Re V, Akgun K, Crothers K, Taddei T, Freiberg M, Justice A. Covid-19 by race and ethnicity: a national cohort study of 6 million united states veterans [Preprint]. Epidemiology; 2020.

94. Roberts J, Dickinson K, Koebele E, Neuberger L, Banacos $\mathrm{N}$, Blanch-Hartigan D, Welton-Mitchell C, Birkland T. Clinicians, cooks, and cashiers: examining health equity and the COVID-19 risks to essential workers. Toxicol Ind Health. 2020;36(9):689-702.

95. Rogers T, Rogers C, VanSant-Webb E, Gu L, Yan B, Qeadan F. Racial disparities in COVID-19 mortality among essential workers in the United States. World Medical \& Health Policy. 2020;12(3):311-27.

96. Rozenfeld Y, Beam J, Maier H, Haggerson W, Boudreau K, Carlson J, Medows R. A model of disparities: risk factors associated with COVID-19 infection. Int J Equity Health. 2020;19(1):126.

97. Scott J, Danos D, Collins R, Simonsen N, Leonardi C, Scribner R, Herd D. Structural racism in the built environment: segregation and the overconcentration of alcohol outlets. Health Place. 2020;64:102385.

98. Shrimali B, Pearl M, Karasek D, Reid C, Abrams B, Mujahid M. Neighborhood privilege, preterm delivery, and related racial/ethnic disparities: an intergenerational application of the index of concentration at the extremes. Am J Epidemiol. 2020;189(5):412-21.

99. Siegel M, Critchfield-Jain I, Boykin M, Owens A. Actual racial/ ethnic disparities in COVID-19 mortality for the Non-Hispanic Black compared to Non-Hispanic White population in 35 US States and their association with structural racism. J Racial Ethn Health Disparities. 2021;1-13.

100. Siegel M, Critchfield-Jain I, Boykin M, Owens A, Nunn T, Muratore R. Actual racial/ethnic disparities in COVID-19 mortality for the Non-Hispanic Black compared to Non-Hispanic White population in 353 US counties and their association with structural racism. J Racial Ethn Health Disparities. 2021.

101. Signorello L, Hargreaves M, Steinwandel M, Zheng W, Cai Q, Schlundt D, Buchowski M, Arnold C, McLaughlin J, Blot W. Southern community cohort study: establishing a cohort to investigate health disparities. J Natl Med Assoc. 2005;97(7):8.

102. Singer M. Down cancer alley: the lived experience of health and environmental suffering in Louisiana's chemical corridor: experience of health and environmental suffering. Med Anthropol Q. 2011;25(2):141-63.

103. Spain D. Race relations and residential segregation in New Orleans: Two centuries of paradox. Ann Am Acad Pol Soc Sci. 1979;441(1):82-96.

104. Tan A, Hinman J, Abdel Magid H, Nelson L, Odden M. Association between income inequality and county-level COVID-19 cases and deaths in the us. J Am Med Assoc. 2021;4(5).

105. Terrell K, James W. Racial disparities in air pollution burden and COVID-19 deaths in Louisiana, USA, in the context of long-term changes in fine particulate pollution. Environ Justice. 2020.

106. Thompson $\mathrm{H}$. Rethinking the politics of white flight in the postwar city: Detroit, 1945-1980. J Urban Hist. 1999;25(2):163-98.

107. Towne S, Probst J, Hardin J, Bell B, Glover S. Health \& access to care among working-age lower income adults in the Great Recession: disparities across race and ethnicity and geospatial factors. Soc Sci Med. 2017;182:30-44.

108. U.S. Census Bureau. QuickFacts New Orleans city, Louisiana. 2019a.

109. U.S. Census Bureau. TIGERline with selected demographic and economic data. U.S. Census Bureau; 2019b.

110. U.S. Department of Health and Human Services. HHS Launches 'Surge' COVID-19 Testing in Hotspot Jurisdictions in Florida, Louisiana and Texas. 2020. 
111. Vahidy F, Nicolas J, Meeks J, Khan O, Pan A, Jones SL, Masud F, Sostman H, Phillips R, Andrieni J, Kash B, Nasir K. Racial and ethnic disparities in SARS-CoV-2 pandemic: analysis of a COVID-19 observational registry for a diverse US metropolitan population. BMJ Open. 2020;10(8).

112. Wallace M, Crear-Perry J, Green C, Felker-Kantor E, Theall K. Privilege and deprivation in Detroit: infant mortality and the index of concentration at the extremes. Int J Epidemiol. 2019;48(1):207-16.

113. Wendland T. New Orleans Will Start Drive-Through Testing For Coronavirus. WWNO. WWNO; 2020.

114. Whittle R, Diaz-Artiles A. An ecological study of socioeconomic predictors in detection of COVID-19 cases across neighborhoods in New York City. BMC Med. 2020;18(1):271.

115. Williams D. Campaigns target COVID-19 vaccine hesitancy among Blacks, but access remains an issue. Buffalo News; 2021.

116. Williams D, Collins C. Racial residential segregation: a fundamental cause of racial disparities in health. Public Health Rep. 2001;116:404-16.

117. Woo B, Kravitz-Wirtz N, Sass V, Crowder K, Teixeira S, Takeuchi D. Residential segregation and racial/ethnic disparities in ambient air pollution. Race Soc Probl. 2019;11(1):60-7.

118. Woods L. Almost "no negro veteran ... could get a loan": African americans, the GI bill, and the NAACP campaign against residential segregation, 1917-1960. J Afr Am Hist. 2013;98(3):392-417.
119. Wu X, Nethery R, Sabath B, Braun D, Dominici F. Exposure to air pollution and COVID-19 mortality in the United States. ISEE Conf Abstr. 2020;2020(1).

120. Yancy C. COVID-19 and African Americans. J Am Med Assoc. 2020;323(19):1891.

121. Yu Q, Salvador C, Melani I, Berg M, Neblett E, Kitayama S. Racial residential segregation and economic disparity jointly exacerbate COVID-19 fatality in large American cities. Ann N Y Acad Sci. 2021;1494(1):18-30.

122. Zhang C, Schwartz G. Spatial disparities in coronavirus incidence and mortality in the United States: an ecological analysis as of May 2020. J Rural Health. 2020;36(3):433-45.

123. Zhang M, Gurung A, Anglewicz P, Yun K. COVID-19 and immigrant essential workers: Bhutanese and Burmese refugees in the United States. Public Health Rep. 2021;136(1):117-23.

124. Zheng Z, Peng F, Xu B, Zhao J, Liu H, Peng J, Li Q, Jiang C, Zhou Y, Liu S, Ye C, Zhang P, Xing Y, Guo H, Tang W. Risk factors of critical \& mortal COVID-19 cases: a systematic literature review and meta-analysis. J Infect. 2020;81(2):e16-25.

Publisher's Note Springer Nature remains neutral with regard to jurisdictional claims in published maps and institutional affiliations. 